\title{
Etnobotânica na Reserva Extrativista Marinha de Arraial do Cabo, RJ, Brasil ${ }^{1}$
}

\author{
Viviane Stern da Fonseca-Kruel ${ }^{2,4}$ e Ariane Luna Peixoto ${ }^{3}$
}

Recebido em 06/05/2003. Aceito em 04/08/2003

\begin{abstract}
RESUMO - (Etnobotânica na Reserva Extrativista Marinha de Arraial do Cabo, RJ, Brasil). A Reserva Extrativista Marinha de Arraial do Cabo (RESEX) localiza-se no município de Arraial do Cabo, região de Cabo Frio. É uma unidade de conservação de interesse ecológico-social e visa proteger o sustento dos pescadores artesanais, a flora e a fauna locais. O clima da região é tropical seco e a vegetação é de restinga. Este estudo objetivou inventariar as espécies vegetais usadas na faixa terrestre da RESEX, associando este conhecimento às tradições locais. As informações etnobotânicas foram obtidas através de observação participante e entrevistas estruturadas com pescadores artesanais. Das 444 citações de uso, catalogou-se 68 espécies, 61 gêneros e 42 famílias. As categorias de uso foram: alimentar (45,6\%), medicinal (39,7\%), tecnológica (29,4\%), lenha (10,2\%), construção $(8,8 \%)$ e ornamental (2,9\%). Utilizou-se o Índice de Shannon para análise da diversidade de espécies resultando: 1,78 (base 10) e 4,10 (base e), denotando que os pescadores possuem bom conhecimento da biodiversidade local, quando comparado a outros estudos da costa brasileira. Os dados obtidos nesta pesquisa possibilitarão a formulação de estratégias de uso sustentável dos recursos naturais, considerando a percepção ambiental da população, baseado nos sistemas cognitivos desenvolvidos ao longo do convívio do homem com a natureza.
\end{abstract}

Palavras-chave: etnobotânica, pescador artesanal, restinga, recursos naturais, Reserva Extrativista

\begin{abstract}
Ethnobotany of Arraial do Cabo Marine Extractive Reserve, Rio de Janeiro, Brazil). The Arraial do Cabo Marine Extractive Reserve (RESEX), is located on Arraial do Cabo Municipality, Cabo Frio region. It is a conservation unit with social and ecological interest, that intends to protect the livelihood of traditional fishermen, local flora and fauna. The climate is tropical dry and the vegetation classified as sandy-coastal-plain vegetation. This study goal was to survey useful species on the land part of RESEX, and associate this knowledge to local traditions. The ethnobotanical data was obtained by observer participation and structured interviews with traditional fishermen. From the 444 use citations, there were 68 species, 61 genera and 42 families. Use categories were as follows: food (45,6\%), medicinal $(39,7 \%)$, technology $(29,4 \%)$, firewood $(10,2 \%)$, construction $(8,8 \%)$ and ornamental $(2,9 \%)$. The Shannon Index was used to analyse the diversity of useful species, with the result of 1,78 (base 10) and 4,10 (base e), showing that the local fishermen have knowledge about the biodiversity, compared to other studies of Brazilian coast. Data from this research will make possible the development of strategies for the sustainable use of natural resources, considering the environment perception of the population, based on cognitive systems developed over time between man and nature.
\end{abstract}

Key words: ethnobotany, traditional fisherman, sandy coastal plains, natural resources, Extractivist Reserve

\section{Introdução}

A Etnobotânica compreende o estudo das sociedades humanas, passadas e presentes, e suas interações ecológicas, genéticas, evolutivas, simbólicas e culturais com as plantas. Pesquisas nesta área facilitam a determinação de práticas apropriadas ao manejo da vegetação com finalidade utilitária, pois empregam os conhecimentos tradicionais obtidos para solucionar problemas comunitários ou para fins conservacionistas (Beck \& Ortiz 1997). Podem também subsidiar trabalhos sobre uso sustentável da biodiversidade através da valorização e do aproveitamento do conhecimento empírico das sociedades humanas, a partir da definição dos sistemas de manejo, incentivando a geração de conhecimento científico e tecnológico voltados para o uso sustentável dos recursos naturais.

Estudos etnobotânicos são importantes, especialmente no Brasil, uma vez que o seu território abriga uma das floras mais ricas do globo, da qual 99,6\% é desconhecida quimicamente (Gotlieb et al. 1996). O território brasileiro conta com grande diversidade de ecossistemas e mais de 200 grupos étnicos diferentes (Brasil 1998). A forte pressão antrópica que os ecossistemas vêm sofrendo tem levado à perda de extensas áreas verdes, da cultura e das tradições das

\footnotetext{
Parte da Dissertação de Mestrado da primeira Autora

2 Instituto de Pesquisas, Jardim Botânico do Rio de Janeiro, R. Pacheco Leão 915, Jardim Botânico, CEP 22460-030, Rio de Janeiro, RJ, Brasil

3 Bolsista da CAPES; (vfonseca@jbrj.gov.br; ariane@jbrj.gov.br)

4 Autor para correspondência: vfonseca@jbrj.gov.br
} 
comunidades que habitam estas áreas, que dependem de recursos do meio para sobreviver. Estes fatores demonstram a necessidade de continuar desenvolvendo estudos sobre Etnobotânica e Botânica Econômica no Brasil (Fonseca \& Sá 1997). Estudos desta natureza tornam-se ainda mais necessários na zona costeira brasileira, onde os diversos ecossistemas que a compõem, como manguezal, restinga, mata atlântica e estuários vêm sendo fortemente impactados devido às atividades de especulação imobiliária e expansão urbana. Fonseca \& Sá (1997) constataram que os trabalhos sobre Etnobotânica e Botânica Econômica desenvolvidos entre 1985 e 1995 além de serem em número reduzido, concentraram-se predominantemente no Estuário Amazônico e na região Sudeste.

Os recursos da biodiversidade são fundamentais para o desenvolvimento econômico, social e cultural das sociedades humanas. A cultura tradicional das populações de pescadores, grupo social com fortes ligações com a natureza, deve ser estudada, protegida e valorizada, pois com isso torna-se maior a probabilidade de assegurar os serviços ambientais dos ecossistemas naturais, combinando a manutenção da cobertura vegetal e a melhoria da qualidade de vida do homem nas áreas onde vivem (Diegues 2000).

O presente estudo visou realizar a análise qualitativa do uso das espécies vegetais da restinga e seus produtos na área da Reserva Extrativista Marinha de Arraial do Cabo, a partir do saber dos pescadores artesanais da Praia Grande, em Arraial do Cabo. Visou também estabelecer a relação entre a disponibilidade e a diversidade dos recursos vegetais utilizados. Buscouse responder às seguintes questões: a comunidade de pescadores artesanais em Arraial do Cabo possui informações sobre a história do uso de plantas da região? Quais são as espécies vegetais reconhecidamente importantes para eles? O conhecimento acumulado pelas sociedades humanas, ao longo do tempo, vem sendo perdido de geração a geração?

\section{Material e métodos}

O estudo foi realizado em áreas de restinga, entre a Praia Grande e Massambaba. Esta restinga localiza-se na faixa terrestre que acompanha a área da Reserva Extrativista Marinha de Arraial do Cabo (RESEX), que inclui uma faixa marinha de três milhas da costa em direção ao mar e 56.769ha de lâmina d'água (Fig. 1). Dista cerca de $180 \mathrm{~km}$ do município do Rio de Janeiro e $14 \mathrm{~km}$ de Cabo Frio. Localiza-se no município de Arraial do Cabo, cuja população é de 23.877 habitantes (IBGE 2001). Tem como coordenadas $22^{\circ} 56^{\prime} 57 \mathrm{~S}$ e $42^{\circ} 04^{\prime} 19 \mathrm{~W}$. Dados da estação meteorológica de Cabo Frio indicam que a precipitação média anual é de $823 \mathrm{~mm}$, a temperatura média é de $23^{\circ} \mathrm{C}$, sendo o calor distribuído o ano todo; a umidade relativa do ar é de $83 \%$ (Araújo 2000; Barbieri 1984). A região de Cabo Frio, na qual Búzios está inserida, é considerada um dos centros brasileiros de alta diversidade de espécies vegetais (Araújo 2000)

As primeiras discussões sobre o estabelecimento da RESEX iniciaram-se em 1993, a partir do contato da Prefeitura Municipal com o Instituto Brasileiro do Meio Ambiente e dos Recursos Naturais Renováveis (IBAMA) e o Centro Nacional de Desenvolvimento Sustentado das Populações Tradicionais (CNPT), visando garantir a exploração auto-sustentável e a conservação dos recursos naturais renováveis tradicionalmente utilizados para pesca artesanal, pelas populações extrativistas locais. Foi a primeira Reserva Extrativista Marinha do Brasil, criada por Decreto Presidencial, em 3 de janeiro de 1997.

O levantamento etnobotânico contou com o conhecimento tradicional dos pescadores artesanais, residentes no entorno da Praia Grande. Foram entrevistados 15 pescadores, dos quais apenas dois não têm como atividade principal a pesca e não são cabistas (nascidos e criados em Arraial do Cabo), porém residem há mais de 30 anos em Arraial do Cabo e estão com freqüência na sede da RESEX. Os entrevistados tinham idades entre 35 e 87 anos, com a seguinte distribuição: 35-45: três pescadores; 46-55: três pescadores; 56-65: cinco pescadores; 66-87: quatro pescadores.

Os termos conhecimento tradicional ou conhecimento popular foi utilizado seguindo Martin (2000) e referem-se ao saber das populações locais sobre o ambiente, e considera-se conhecimento científico como a informação derivada da pesquisa.

Foram realizadas viagens mensais a campo, no período de março/2000 a julho/2001. Os primeiros meses do trabalho de campo foram destinados à determinação dos locais onde os pescadores reconhecem a vegetação de restinga e dela fazem uso. Posteriormente, foram realizadas técnicas de observações diretas em caminhadas livres (walk-in-the-woods) com os pescadores, para coleta de material botânico e anotação de informações sobre o uso das espécies (Phillips \& Gentry 1993; Alexiades 1996).

As entrevistas, estruturadas e semi-estruturadas, foram gravadas e anotadas, bem como realizou-se 


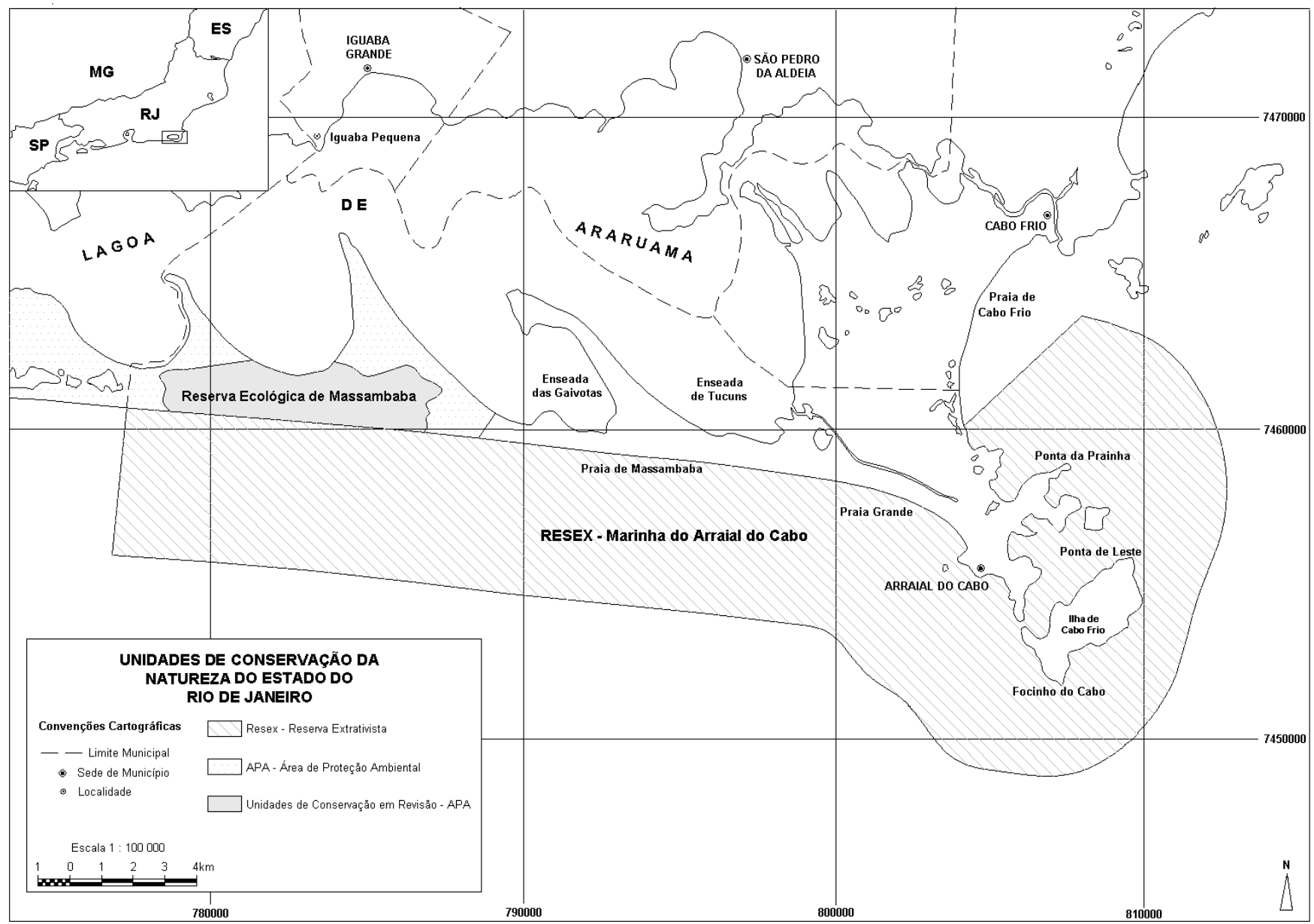

Figura 1. Mapa da Reserva Extrativista Marinha de Arraial do Cabo, RJ. (Fonte: Adaptado do Atlas das Unidades de Conservação da Natureza, Governo do Estado do Rio de Janeiro / SEMA, 2001).

observação direta. Buscou-se prioritariamente o conhecimento que os pescadores demonstravam sobre a história do uso de plantas e sobre o ambiente. Cada informante foi entrevistado individualmente, utilizando-se questionários, seguindo a técnica da listagem livre (free listing), cuja idéia central é a cultura como conhecimento, portanto, aprendida e repassada na população (Bernard 1989). Elaborouse questionário com perguntas abertas e fechadas para cada uma das espécies vegetais citadas, além da verificação in loco destas espécies, e posterior confirmação destas informações com outros pescadores. Procederam-se também à coleta, herborização e depósito dos exemplares testemunhos nos Herbários da Universidade Federal Rural do Rio de Janeiro (RBR) e Instituto de Pesquisas Jardim Botânico do Rio de Janeiro (RB). Essa metodologia foi adaptada das práticas de campo sugeridas por Alexiades (1996).
Foi elaborado um registro para cada espécie vegetal indicada como útil, contendo: nome científico, família, nome comum, localização, forma de vida, habitat, uso(s), parte utilizada, nome do informante, nome e número do coletor do espécime botânico. As categorias de uso adotadas foram: construção, medicinal, alimentar, tecnologia, lenha e ornamental.

Além da análise e discussão dos dados da pesquisa buscou-se compará-los com dados oriundos de pesquisas etnobotânicas realizadas em localidades costeiras da América do Sul. Foi utilizado o índice de diversidade de Shannon ( $H^{\prime}$ ) (Magurran 1988) para o estabelecimento de comparações entre os resultados obtidos neste estudo com trabalhos similares, com a seguinte fórmula: $\mathrm{H}^{\prime}=$ - $\sum p i \ln p i$, sendo: $\mathrm{H}^{\prime}=$ índice de diversidade de Shannon, onde: $\mathrm{pi}=\mathrm{ni} / \mathrm{N}=\mathrm{DR} ; \mathrm{ni}=$ número de vezes que uma espécie (i) foi considerada útil por cada informante; $\mathrm{N}=$ número total de vezes em que as espécies foram consideradas úteis pelos informantes. 


\section{Resultados e discussão}

Histórico e Atividades Sócio-Econômicas - Registros em sambaquis, de aproximadamente 8.000 anos marcam a ocupação humana no litoral do Estado do Rio de Janeiro. Há registros de grupos de pescadores pré-históricos que percorreram o litoral de Itaipu-Niterói e Cabo Frio, fixando-se preferencialmente nas áreas de restingas. Desenvolveram atividades mistas de pescadores ou coletores com aproveitamento do meio ambiente, utilizando fauna e flora local, além da matéria prima para a confecção dos artefatos líticos (Kneip \& Pallestrini 1984).

Após o descobrimento do Brasil, os colonizadores aprenderam a viver da nova terra, misturando seus conhecimentos àqueles adquiridos com os índios que ali habitavam. Apreenderam novas técnicas e ao mesmo tempo introduziram instrumentos e materiais à cultura local. Com o passar dos anos a população descendente principalmente de portugueses, devido ao isolamento geográfico e econômico, foi obrigada a produzir seus objetos de uso doméstico, exercendo assim atividade profissional como artesãos. Este isolamento permaneceu durante muitos anos por Arraial do Cabo ser, praticamente, um cabo de terra, com poucas ligações de estradas, sendo o porto a principal via de ligação (Prado 2002). A economia local era baseada na pesca que inclui, além da lida no mar, a confecção de cestos de bambus e cipós e redes. Prado (2002) informou que destes artefatos, atualmente aparecem apenas redes pequenas, tarrafas ou pequenos cestos. Ainda hoje, entretanto, sejam nas práticas usuais, seja na memória do pescador cabista, há registros que apontam para a combinação de saberes indígena e europeu.

A implantação, em Arraial do Cabo, de uma indústria salineira, a Companhia Nacional de Álcalis (CNA), a maior produtora de sal do Brasil e a única produtora de barrilha da América do Sul na época (Álcalis 2001), promoveu grandes mudanças sociais, culturais e ambientais. Segundo Araujo (1965), antes da sua instalação, Arraial do Cabo era um povoado rústico de pescadores constituído por poucas famílias que se inter cruzavam. Com a produção industrial, a região de Cabo Frio passou a adotar padrões urbanos de grandes centros industriais brasileiros, passando o trabalho remunerado na fonte a ser forte atrativo, especialmente entre a população jovem (Fontenelle 1960).

Atualmente, a pesca artesanal é exercida por pescadores autônomos, isolados ou em parcerias. A remuneração é feita pelo sistema tradicional de divisão da produção em "partes", sendo o produto destinado principalmente ao mercado. Da pesca retiram a maior parte de sua renda. Arraial do Cabo, apesar de permanecer com estrutura física de uma pequena vila, possui estrutura industrial, sistema estabelecido de distribuição de água, luz e gás, um hospital e alguns postos de saúde. As escolas locais oferecem apenas o ensino fundamental, o que se reflete na escolaridade dos pescadores cabistas e seus filhos; a maioria tem apenas o ensino fundamental.

As casas, de modo geral, têm a seguinte disposição: a frente, local onde a família estendia a esteira nas calmarias; os fundos, reservados para serviços domésticos e de um dos lados, às vezes uma pequena horta. Fontenelle (1960) cita esta mesma disposição, bem como o tipo de construção em pau-a-pique. Descreve que a casa em Arraial, até os anos 40, era construída por quatro postes fincados em retângulos, unidos superiormente por quatro barrotes, como uma espécie de armação de mesa. As madeiras mais usadas eram ipê (Tabebuia sp.), garaúna (Melanoxylon brauna Schott), bacupari (Garcinia brasiliensis Mart.), maçaranduba (Lucuma procera Mart.) entre outras espécies locais. Os intervalos eram preenchidos por ripas verticais de madeira menos espessa, ou com a palmeira de tucum (Bactris setosa Mart.). O teto era feito com caibros mais finos e o chão, de barro umedecido e batido. Essa casa de pau-a-pique tinha duração de cerca de sete anos e as casas de tijolos e telhas chegam até 30 anos.

Informantes e a História de Vida - O processo de transformação social dos moradores de Arraial do Cabo, principalmente dos nativos, foi estudado por Prado (2002) assim como as transformações de uma economia extrativista para uma economia mista e a implantação da RESEX como revigorador da profissão de pescador.

Em Arraial do Cabo os pescadores se definem como pescadores cabistas e artesanais.

Cabista é quando pai e a mãe são nascidos no Arraial. Cabista é nascido e criado aqui, ele vive da pesca". O verdadeiro pescador artesanal é o cabista, porque ele carrega uma canoa a remo na mão [...] (Sr. Chonca).

$\mathrm{Na}$ maioria, são descendentes de portugueses, alguns de italianos. Poucos são negros ou descendentes diretos de indígenas, embora reconheçam a forte influência dos índios Tamoios na região.

Segundo eles, atualmente são poucos (cerca de dez) os pescadores artesanais ainda vivos. A maioria dos jovens pescadores vem do Estado do Espírito Santo e de Campos, no Rio de Janeiro, não sendo, portanto cabistas. Instalam-se em Arraial do Cabo e aí residem e pescam. 
Britto (1999) estudando a construção da identidade social dos pescadores de Arraial do Cabo, afirmou que ser cabista, não significa apenas ser "natural" de Arraial do Cabo, mas implica em pertencer a um sistema social determinado no tempo e no espaço, no qual se inscrevem valores, símbolos e histórias de vida comuns.

Entre os pescadores de Arraial do Cabo, o termo caiçara é pejorativo e sinônimo de pessoa que não gosta de trabalhar. $\mathrm{O}$ termo caiçara tem origem no vocábulo Tupi-Guarani caá-içara (Sampaio 1987) que era utilizado para denominar as estacas colocadas em torno das tabas ou aldeias, e o curral feito de ramos de árvores fincados na água para cercar o peixe. Ao longo dos anos, passou a ser o nome dado às palhoças construídas nas praias para abrigar as canoas e os apetrechos dos pescadores e, mais tarde, para identificar os indivíduos e/ou comunidades do litoral dos Estados do Paraná, São Paulo e Rio de Janeiro (Diegues 1988; Adams 2000). São várias as semelhanças notadas entre os pescadores artesanais de Arraial do Cabo e os caiçaras do litoral de São Paulo, estudados por Adams (2000) como a função da mulher e do homem em ambas as sociedades e a estrutura das casas.

A alimentação do pescador, no passado era baseada no peixe e no que era extraído das pequenas lavouras e hortas. Costumava fazer duas ou três refeições diárias. A organização de lavouras e hortas seguia, basicamente, o mesmo padrão: eram pequenas, somente para subsistência e mantidas na parte de trás das casas. Cultivavam a batata, a mandioca, o milho e o feijão e algumas verduras.

[...] hoje em dia não tem agricultura aqui mas o pescador tinha uma rocinha que chamava de rancho [...] Dai tinha sempre, no quintal de casa, uma horta. Plantava couve, alface, tomate, uma mandioca, o aipim, o feijão (Sr. Alex).

O pescador dependia da venda do peixe para sobreviver. A moeda circulava em função da quantidade do pescado e do preço negociado.

Nos anos 40 Arraial do Cabo era uma vila de pescadores, a Companhia Nacional de Álcalis estava começando. O peixe não tinha grande valor, era comercializado somente salgado ... Todo o peixe que se pescava aqui, ia pro sal, e ai uma pessoa arrematava em leilão. Vendia por cento [...] Tinha um barracão chamado paiol que chegava ali, limpava, tirava as vísceras e salgava os peixes, punham num tanque e ficava ali. Depois de um certo tempo, eles eram levados em mala ... O peixe salgado era transportado em tropa de burro, saía de Arraial, Cabo Frio, São Pedro, Iguaba, Araruama, Boa
Esperança, Itaborai, Rio Bonito, Silva Jardim [...] era sempre a mesma linha e tinha outra linha daqui para o outro lado, de Campos, São Fidélis. Eles levavam 15 dias, 20 dias [...] pra retornar com o dinheiro para pagar o pescador. É como hoje, o pescador vende ao dono da peixaria, só que ele leva o peixe pro Rio e no dia seguinte ele tem condições de pagar (Sr. Chonca).

O papel da mulher no passado de Arraial era definido apenas como dona de casa, mãe, rendeira (de bilro) e salgadeira de peixe. Fontenelle (1960) descreveu que a mulher, além destas funções, periodicamente cortava lenha para cozinhar, nas matas de restinga e em outros morros que circundavam o povoado. A madeira e o carvão foram combustíveis utilizados até a substituição por querosene, após os anos 50. Além de realizar estas funções, a mulher era responsável até os anos 70, por prover a casa com água potável, buscando água em cacimbas, poços e bicas da CNA.

A maioria dos pescadores são católicos, porém outras religiões parecem crescer entre eles. Alguns esporadicamente, freqüentam centros espíritas mas mesmo assim afirmam ser católicos.

Em Arraial do Cabo existiam rezadeiras, mulheres que através de orações e usos de plantas medicinais exerciam o poder da cura à doentes. Estas passaram seus ensinamentos às filhas e atualmente, estas práticas são raras. Nas entrevistas, pode-se verificar esta tradição, bem como a citação de um curandeiro, chamado curandor.

No Arraial tinha muita rezadeira. A minha mãe era rezadeira de espinhela (Sr. Chonca).

A Restinga e a percepção do ambiente pelos pescadores cabistas - Os pescadores artesanais têm informação acumulada, passada de geração a geração, sobre o ambiente, regime dos ventos, marés e vegetação. Conhecem frutos comestíveis e épocas de frutificação, plantas medicinais e madeiras utilizadas na construção, consertos de canoas, confecção de artefatos e utensílios. Conhecem bem a restinga, uma vez que esta faz parte da sua vida cotidiana. Os mais antigos afirmaram que seus pais saíam de Arraial do Cabo e caminhavam até Saquarema pela restinga, para pescar, com apenas uma cuia para beber água, e saciava a fome com os frutos comestíveis.

Eles definem a restinga como sendo um local onde há muita areia. A planta característica e indicadora de restinga é o guriri, ou coco-guriri (Allagoptera arenaria). Reconhecem diferentes áreas de restinga, como: 1) restinga baixa, com plantas rasteiras, ou ervas; 2) restinga alta ou mata, mata com árvores de mais de 
$8 \mathrm{~m}$ de altura; 3) duna, montes altos de areia, sem nenhum tipo de vegetação; 4) lagamar ou enseada da restinga, local onde a água do mar bate e fica represada. Ocupava quase $5 \mathrm{~km}$ de extensão da Praia Grande. Atualmente não é mais observado devido à deposição de barrilha e dejetos da CNA (Sr. Chonca).

A pesquisa realizada identificou 68 espécies distribuídas em 61 gêneros e 42 famílias botânicas, entre as plantas citadas pelos informantes. As famílias mais representativas em número de espécies foram Myrtaceae (9 espécies), Asteraceae (4), Cactaceae (4), Anacardiaceae (3) e Leguminosae (3); as demais apresentaram apenas de uma a duas espécies. Foram catalogadas 36 diferentes usos para as espécies, ordenados em seis categorias distintas (Tab. 1). Os informantes indicaram 31 espécies alimentares, 27 medicinais, 20 aplicadas em tecnologia, como construção e consertos de barcos, peças e utensílios, sete como lenha, seis em construção e duas como ornamentais. Muitas espécies têm usos múltiplos (Tab. 2 e 3), ou seja, mais de um uso associado (Fig. 2).

Os frutos foram a parte dos vegetais mais citados como úteis, totalizando $28 \%$ das espécies (19 espécies); em seguida as folhas, $21 \%$ (14 espécies); o lenho $15 \%$ (10 espécies). Os 36\% restantes foram referentes a plantas das quais são extraídos fruto e lenho; fruto e folha; folha e raiz; folha e flor; fruto, folha e lenho; casca e raiz.

O hábito de vida mais encontrado foi o herbáceo (38\%), seguido de arbóreo (37\%), arbustivo (21\%) e trepadeira (4\%). A maioria das espécies indicadas e citadas pelos informantes, encontra-se na mata de restinga (43\%); as demais foram coletadas na restinga aberta (35\%) outras são espécies cultivadas em quintais e hortas $(16 \%)$ e $6 \%$ são plantas ruderais da restinga ou entorno de suas casas.

Os pescadores citam que a restinga é rica em saborosos e nutritivos frutos, entre os quais destacamse representantes de Myrtaceae, como a pitanga (Eugenia uniflora), o cambuí ou cambuim (E. arenaria), a gabiroba (Campomanesia guazumifolia), o araça (Psidium cattleyanum), o marmelo (Eugenia sp.), a azeitona (E. olivacea), a pitangobaia (E. ovalifolia). Citam ainda outras espécies, como bacupari (Garcinia brasiliensis), o murici (Byrsonima sericea), o coco-de-tucum (Bactris setosa), o bajirú (Chrysobalanus icaco), o cajú (Anacardium occidentale), e alguns cactos, chamados na região de cardeiro (Tab. 2).

O guriri, também chamado de coquinho-da-praia (Allagoptera arenaria), apresenta pequenos frutos bastante apreciados na região, sendo consumidos diretamente quando maduros, durante as longas travessias para pescar ou após ser amassado no pilão, junto com a farinha de mandioca, na hora do café.

Algumas plantas fazem parte da cultura e tradição local, como a aroeira (Schinus terebinthifolius) e o murici (Byrsonima sericea). Estas duas plantas eram usadas para tingir rede de pesca, evitando assim o ataque

Tabela 1. Usos da vegetação de restinga pelos pescadores artesanais da Praia Grande, Arraial do Cabo, RJ (Listagem por categorias adaptado de Galleano 2000).

Construção

Fundações da casa

Tábuas para o chão e teto

Esteio de casas (peças para escorar paredes)

Medicinal

Remédio para doenças pulmonares e tosse

Remédio para problemas digestivos

Remédio para problemas de fígado e sangue

Remédio para controlar a taxa de açúcar no sangue, diabetes

Calmante

Antiinflamatório

Cicatrizante

Anti-séptico

Banho como remédio na limpeza dos olhos em casos de "dor d'olhos", ou seja, conjuntivite

Banho contra "mal olhado", "descarrego", para espantar "maus espíritos"

Contra anemia e impaludismo

Infuso de folhas em álcool contra dores na coluna, braços e pernas

Alimentar

Frutos consumidos diretamente, crus

Frutos usados em refrescos ou sucos

Frutos comestíveis para animais (pássaros)

Tempero

Tecnologia

Confecção de agulhas para costurar redes de pesca (madeira)

Da fibra da folha confecciona-se linha para pesca

Confecção de caverna de barco

Consertos de barco

Contorno para barco ou canoa

Vara e "forcada" para arrastar a rede de pesca

Vara para transportar peixe na feira

Sabão

Látex retirado para auxiliar na caça

Raízes para confecções de bóias em rede de espera para peixes

Raízes cozidas tingem redes de pesca

Confecção de bilrros, utensílio das rendeiras para bordar

Confecção de enchimento de travesseiros

Utensílios

Lenha

Madeira retirada para lenha de forma geral ou para uso em fogão à lenha

Ornamental

Planta utilizada como ornamental ao redor das casas e jardins 
Tabela 2. Lista de espécies encontradas na restinga ou próximo de áreas de restinga, citadas como úteis pelos pescadores artesanais da Praia Grande, Arraial do Cabo/RJ, ordenadas por ordem alfabética de famílias botânicas (Uso: Al-alimentar, Me-medicinal, Tc-tecnologia, Cs-construção, La-lenha, Or-ornamental; Parte usada: Fo-folha, Fl-flor, Fr-fruto, Se-semente, Ca-casca, Rz-raiz, Ln-lenho, Lx-látex, Tp-toda a planta; Hab.- hábito: Arv- arbóreo, Arb-arbustivo, Herb-herbáceo, Tre- trepadeira; Hat.- habitat: Mr-mata de restinga, Ra-restinga aberta, C-cultivada, Ru-ruderal e subespontânea).

\begin{tabular}{|c|c|c|c|c|c|c|}
\hline Família/Nome Científico & Nome local & Uso & Parte usada & Hab. & Hat. & N. Col. ${ }^{1}$ \\
\hline \multicolumn{7}{|l|}{ ANACARDIACEAE } \\
\hline Anacardium occidentale L.* & caju & $\mathrm{Al}, \mathrm{Me}$ & $\mathrm{Fr}$ & Arv & $\mathrm{Ra}$ & 378 \\
\hline Schinus terebinthifolius Raddi & aroeira & $\mathrm{Me}, \mathrm{Tc}, \mathrm{Cs}, \mathrm{Al}$ & $\mathrm{Ca}, \mathrm{Rz}$ & Arb & $\mathrm{Mr}$ & 535 \\
\hline Tapirira guianensis Aubl. & & $\mathrm{Tc}$ & $\mathrm{Ca}$ & Arv & $\mathrm{Mr}$ & 551 \\
\hline \multicolumn{7}{|l|}{ ANNONACEAE } \\
\hline Annona glabra L. & araticum & $\mathrm{Tc}$ & $\mathrm{Rz}$ & Arv & $\mathrm{Ra}$ & 557 \\
\hline Annona squamosa L. * & fruta-de-conde & $\mathrm{Al}$ & $\mathrm{Fr}$ & Arv & $\mathrm{C}$ & - \\
\hline \multicolumn{7}{|l|}{ Apocynaceae } \\
\hline Aspidosperma parvifolium A. DC. & ipequeá & $\mathrm{Cs}, \mathrm{Tc}$ & $\mathrm{Ln}$ & Arv & $\mathrm{Mr}$ & 369 \\
\hline \multicolumn{7}{|l|}{ ARACEAE } \\
\hline \multicolumn{7}{|l|}{ ARECACEAE } \\
\hline Allagoptera arenaria (Gomes) Kuntze & coquinho-de-guriri; guriri; & $\mathrm{Al}$ & $\mathrm{Fr}$ & Herb & $\mathrm{Ra}$ & 484 \\
\hline Bactris setosa Mart. & coco-tucum, tucum & $\mathrm{Al}, \mathrm{Tc}$ & Fr, Fo & Arb & $\mathrm{Mr}$ & 351 \\
\hline \multicolumn{7}{|l|}{ ASTERACEAE } \\
\hline Achyrocline satureioides (Lam.) DC. & macela & $\mathrm{Me}, \mathrm{Tc}$ & $\mathrm{Td}$ & Herb & $\mathrm{Ru}$ & 479 \\
\hline Baccharis trimera (Less.) DC. * & carqueja & $\mathrm{Me}$ & Fo & Herb & $\mathrm{Ra}$ & 500 \\
\hline Matricaria recutita $\mathrm{L} . *$ & camomila & $\mathrm{Me}$ & $\mathrm{Fl}$ & Herb & $\mathrm{C}$ & - \\
\hline Vernonia condensata Baker* & assa-peixe & $\mathrm{Me}$ & Fo & Arb & $\mathrm{C}$ & 503 \\
\hline \multicolumn{7}{|l|}{ BIGNONIACEAE } \\
\hline $\begin{array}{l}\text { Tabebuia cassinoides (Lam.) DC. } \\
\text { BORAGINACEAE }\end{array}$ & ipê & $\mathrm{Tc}$ & $\mathrm{Ln}$ & Arv & $\mathrm{Mr}$ & 349 \\
\hline Cordia verbenacea DC. & caimbê-preto & $\mathrm{Al}, \mathrm{Me}$ & Fr, Fo & Arb & $\mathrm{Ru}$ & 550 \\
\hline \multicolumn{7}{|l|}{ BROMELIACEAE } \\
\hline \multicolumn{6}{|l|}{ CACTACEAE } & 487 \\
\hline Melocactus violaceus Pfeiff. & cabeça-de-frade & Or & $\mathrm{Tp}$ & Herb & $\mathrm{Ra}$ & - \\
\hline Opuntia brasiliensis (Willd.) Haw. & arumbeba & $\mathrm{Al}$ & $\mathrm{Fr}$ & Arv & $\mathrm{Mr}$ & 485 \\
\hline Pilosocereus arrabidae (Lem.) Byl. \& Row. & cardeiro; cardo & Or, $\mathrm{Al}$ & $\mathrm{Fr}$ & Herb & $\mathrm{Ra}$ & 572 \\
\hline $\begin{array}{l}\text { Selenicereus setaceus (Salm-Dyck) } \\
\text { A.Berger ex Werderm. }\end{array}$ & mandacaru & $\mathrm{Me}$ & $\mathrm{Tp}$ & Herb & $\mathrm{Ra}$ & 571 \\
\hline \multicolumn{7}{|l|}{ CAPPARACEAE } \\
\hline Capparis flexuosa (L.) L. & timbó & $\mathrm{La}$ & Ln & Tre & $\mathrm{Mr}$ & 555 \\
\hline \multicolumn{7}{|l|}{ CECROPIACEAE } \\
\hline Cecropia glaziovi Snethlage & embaúba & $\mathrm{Me}$ & $\mathrm{Fl}$ & Arv & $\mathrm{Mr}$ & 483 \\
\hline \multicolumn{7}{|l|}{ CELASTRACEAE } \\
\hline \multicolumn{7}{|l|}{ CHENOPODIACEAE } \\
\hline Chenopodium sp. & erva-de-santa-maria & $\mathrm{Me}$ & Fo & Herb & $\mathrm{Ra}$ & 540 \\
\hline \multicolumn{7}{|l|}{ CHRYSOBALANACEAE } \\
\hline \multicolumn{7}{|l|}{ CLUSIACEAE } \\
\hline Clusia fluminensis Planch. \& Triana & abaneiro & $\mathrm{Me}$ & Fo & Arv & $\mathrm{Ra}$ & 475 \\
\hline Garcinia brasiliensis Mart. & bacupari & $\mathrm{Al}$ & $\mathrm{Fr}$ & Arb & $\mathrm{Ra}$ & 334 \\
\hline \multicolumn{7}{|l|}{ COMBRETACEAE } \\
\hline Terminalia catappa L.* & amendoeira & $\mathrm{Al}$ & $\mathrm{Fr}$ & Arv & $\mathrm{Mr}$ & 510 \\
\hline \multicolumn{7}{|l|}{ COMMELINACEAE } \\
\hline Dichorisandra thyrsiflora J.C. Mikan & cana-do-brejo & $\mathrm{Me}$ & Fo & Herb & $\mathrm{Ra}$ & 467 \\
\hline CRASSULACEAE & & & & & & \\
\hline Kalanchoe brasiliensis Cambess.* & saião & $\mathrm{Me}$ & Fo & Herb & $\mathrm{C}$ & - \\
\hline CUCURBITACEAE & & & & & & \\
\hline Momordica charantia L. * & melão-de-são-caetano & $\mathrm{Me}$ & Fo & Herb & $\mathrm{C}$ & 287 \\
\hline
\end{tabular}


Tabela 2 (continuação)

\begin{tabular}{|c|c|c|c|c|c|c|}
\hline Família/Nome Científico & Nome local & Uso & Parte usada & Hab. & Hat. & N. Col. ${ }^{1}$ \\
\hline \multicolumn{7}{|l|}{ EUPHORBIACEAE } \\
\hline Ricinus communis L. * & mamona & $\mathrm{Me}$ & $\mathrm{Se}$ & Herb & $\mathrm{Ru}$ & 489 \\
\hline Sebastiania glandulosa (Sw.) Müll. Arg. & fruta-de-leite & $\mathrm{Al}$ & $\mathrm{Fr}$ & Arb & $\mathrm{Mr}$ & 564 \\
\hline \multicolumn{7}{|l|}{ LAMIACEAE } \\
\hline Indet. & parietália & $\mathrm{Me}$ & Fo & Herb & $\mathrm{C}$ & 552 \\
\hline Plectranthus barbatus Andr.* & boldo & $\mathrm{Me}$ & Fo & Herb & $\mathrm{C}$ & - \\
\hline \multicolumn{7}{|l|}{ LEGUMINOSAE } \\
\hline $\begin{array}{l}\text { Chloroleucon tortum (Mart.) Pittier ex } \\
\text { Barneby \& J.W. Grimes }\end{array}$ & jacaré & $\mathrm{La}$ & $\mathrm{Ln}$ & Arv & $\mathrm{Mr}$ & - \\
\hline Inga laurina $(\mathrm{Sw}$.$) Willd.$ & ingá-mirim & $\mathrm{Al}, \mathrm{Tc}$ & Fr, Ln & Arv & $\mathrm{Mr}$ & 530 \\
\hline $\begin{array}{l}\text { Inga subnuda Salzm. subsp. luschnathiana } \\
\text { (Benth.) T.D. Pelm. }\end{array}$ & ingá & $\mathrm{Al}, \mathrm{Tc}$ & Fr, Ln & Arv & $\mathrm{Mr}$ & 516 \\
\hline \multicolumn{7}{|l|}{ LORANTHACEAE } \\
\hline Psittacanthus sp. & fruta de capivara & $\mathrm{Al}$ & $\mathrm{Fr}$ & Tre & $\mathrm{C}$ & 568 \\
\hline \multicolumn{7}{|l|}{ MALPIGHIACEAE } \\
\hline Byrsonima sericea DC. & murici & $\mathrm{Tc}$ & $\mathrm{Rz}, \mathrm{Ca}$ & Arb & $\mathrm{Ra}$ & 482 \\
\hline \multicolumn{7}{|l|}{ MYRSINACEAE } \\
\hline Myrsine parvifolia A. DC. & capororoca & $\mathrm{La}$ & $\mathrm{Ln}$ & Arv & $\mathrm{Mr}$ & 352 \\
\hline \multicolumn{7}{|l|}{ MYRTACEAE } \\
\hline $\begin{array}{l}\text { Campomanesia guazumifolia } \\
\text { (Cambess.) O. Berg }\end{array}$ & gabiroba & $\mathrm{Al}, \mathrm{Tc}$ & Fr & Arv & $\mathrm{Mr}$ & 469 \\
\hline Eugenia arenaria Cambess. & cambuí & $\mathrm{Al}$ & $\mathrm{Fr}$ & Herb & $\mathrm{Ra}$ & 566 \\
\hline Eugenia olivacea O. Berg. & azeitona & $\mathrm{Al}$ & $\mathrm{Fr}$ & Herb & $\mathrm{Ra}$ & 480 \\
\hline Eugenia ovalifolia Cambess. & pitangobaia & $\mathrm{Al}, \mathrm{La}$ & Fr, Ln & Herb & $\mathrm{Ra}$ & 534 \\
\hline Eugenia sp. & marmelo & Al & $\mathrm{Fr}$ & Arb & $\mathrm{Ra}$ & 567 \\
\hline Eugenia olivacea $\mathrm{O}$. Berg. & azeitona & $\mathrm{Al}$ & $\mathrm{Fr}$ & Herb & $\mathrm{Ra}$ & 480 \\
\hline Eugenia uniflora $\mathrm{L}$. & pitanga & $\mathrm{Cs}, \mathrm{Tc}, \mathrm{Me}, \mathrm{Al}$ & Fr, Fo, Ln & Herb & $\mathrm{Ra}, \mathrm{Mr}$ & 537,554 \\
\hline Myrciaria tenella (DC.) O. Berg & murta, cambuí murtinha & $\mathrm{Tc}, \mathrm{Me}$ & Fo & Arv & $\mathrm{Mr}$ & 553 \\
\hline Neomitranthes obscura (DC.) Silveira & bapuana & $\mathrm{Al}, \mathrm{Tc}$ & Fr, Ln & Arb & $\mathrm{Ra}$ & 556 \\
\hline Psidium cattleyanum Sabine & araçá-do-mato & $\mathrm{Al}$ & Fr & Arv & $\mathrm{Mr}$ & 565 \\
\hline \multicolumn{7}{|l|}{ NYCTAGINACEAE } \\
\hline Boerhavia diffusa L. * & batata-tostão & $\mathrm{Me}$ & $\mathrm{Rz}$ & Herb & $\mathrm{C}$ & - \\
\hline \multicolumn{7}{|l|}{ OCHNACEAE } \\
\hline Ouratea sp. & guapeba & $\mathrm{Al}$ & Fr & Arv & $\mathrm{Mr}$ & 491 \\
\hline \multicolumn{7}{|l|}{ PASSIFLORACEAE } \\
\hline Passiflora edulis Sims & maracutão & $\mathrm{Al}$ & $\mathrm{Fr}$ & Tre & $\mathrm{Mr}$ & 288 \\
\hline Passiflora jilekii Wawra & maracujá & $\mathrm{Al}$ & $\mathrm{Fr}$ & Tre & $\mathrm{Mr}$ & 524 \\
\hline \multicolumn{7}{|l|}{ PHYTOLACCACEAE } \\
\hline Petiveria alliacea L. * & guiné, piu-piu-guiné & $\mathrm{Me}, \mathrm{Tc}$ & Fo, Ln & Herb & $\mathrm{C}$ & 407 \\
\hline \multicolumn{7}{|l|}{ PIPERACEAE } \\
\hline Piper amalago L. var. medium(Jacq.) Yunck & aperta-ruão & $\mathrm{Me}$ & Fo & Arb & $\mathrm{Mr}$ & 514 \\
\hline \multicolumn{7}{|c|}{ POACEAE } \\
\hline Cymbopogon citratus (DC.) Stapf* & capim-limão & $\mathrm{Me}$ & Fo & Herb & $\mathrm{C}$ & - \\
\hline \multicolumn{7}{|l|}{ POLYGONACEAE } \\
\hline Coccoloba alnifolia Casar. & folha-de-prata & Cs & $\mathrm{Tp}$ & Arb & $\mathrm{Ra}$ & 478 \\
\hline \multicolumn{7}{|l|}{ RHAMNACEAE } \\
\hline Condalia buxifolia Reissek & saputiaba-mirim & $\mathrm{Al}$ & Fr & Arv & $\mathrm{Mr}$ & 559 \\
\hline Scutia arenicola (Casar.) Reissek & arribeira, ribeira & $\mathrm{Al}, \mathrm{Tc}, \mathrm{Ln}$ & Fr, Ln & Arv & $\mathrm{Mr}$ & 536 \\
\hline \multicolumn{7}{|l|}{ RUTACEAE } \\
\hline Citrus sinensis (L.) Osbeck.* & laranja da terra & $\mathrm{Al}, \mathrm{Me}$ & Fo, Fl & Arb & $\mathrm{C}$ & - \\
\hline \multicolumn{7}{|l|}{ SAPINDACEAE } \\
\hline Allophylus puberulus Radlk. & estaladeira & $\mathrm{La}$ & $\mathrm{Ln}$ & Arv & $\mathrm{Mr}$ & 518 \\
\hline \multicolumn{7}{|l|}{ SAPOTACEAE } \\
\hline Pouteria grandiflora (A.DC.) Baelni & visgo & $\mathrm{Tc}$ & $\mathrm{Lx}$ & Arb & $\mathrm{Mr}$ & 471 \\
\hline Sideroxylon obtusifolium (Roem. \& & saputiquiaba & $\mathrm{Cs}, \mathrm{Tc}$ & $\mathrm{Ln}$ & Arv & $\mathrm{Mr}$ & 519 \\
\hline
\end{tabular}




\begin{tabular}{|c|c|c|c|c|c|c|}
\hline Família/Nome Científico & Nome local & Uso & Parte usada & Hab. & Hat. & N. Col. ${ }^{1}$ \\
\hline \multicolumn{7}{|l|}{ SIMAROUBACEAE } \\
\hline Picraminia rhamiflora Planch. & imbiu & Cs & Ln & Arv & $\mathrm{Mr}$ & 560 \\
\hline \multicolumn{7}{|l|}{ SMILACACEAE } \\
\hline Smilax rufescens Griseb. & japecanga & $\mathrm{Me}$ & Fo, $\mathrm{Rz}$ & Herb & $\mathrm{Ra}$ & 573 \\
\hline \multicolumn{7}{|l|}{ SOLANACEAE } \\
\hline Cestrum laevigatum Schltdl. & canema & $\mathrm{Me}$ & Fo & Arb & $\mathrm{Ru}$ & 561 \\
\hline \multicolumn{7}{|l|}{ ULMACEAE } \\
\hline Trema micrantha (L.) Blume & corindiba, curindiba & $\mathrm{Tc}$ & $\mathrm{Ln}$ & Arv & $\mathrm{Mr}$ & 570 \\
\hline \multicolumn{7}{|l|}{ VERBENACEAE } \\
\hline Stachytarpheta canescens Kunth & gervão & $\mathrm{Me}$ & Fo & Herb & $\mathrm{Ra}$ & 424 \\
\hline
\end{tabular}

${ }^{1}$ Os números referem-se às coletas de V.S. da Fonseca-Kruel; * Espécies não naturais do ecossistema restinga

excessivo dos peixes à rede. A preferência pelo murici, destacada nos relatos dos pescadores, deve-se ao fato da aroeira, quando usada em grande quantidade, provocar queimaduras na pele. O processo de retirada do pigmento do murici consiste na coleta de raíz e casca que após serem bem "socadas" são colocadas na canoa, junto com água do mar, e por fim a rede de pesca para curtir alguns dias ao sol.

Entre as espécies da mata de restinga empregadas como madeireiras, na construção de casas, embarcações, fornecedoras de lenha, destaca-se a saputiquiaba (Sideroxylon obtusifolia). É empregada em consertos de canoas, pois lhe é atribuída alta resistência ao tempo e de certa forma, impermeabilidade. Existem regras para coleta de espécies para tais fins.

A madeira boa, depende da lua. Em lua cheia a madeira coletada apodrece mais rápido, entra água e racha com mais facilidade (Sr. Chonca).

As plantas medicinais são também de grande valor para os pescadores. As folhas do bajirú ou abajirú (Chysobalanus icaco), foram intensamente indicadas para problemas de diabetes ou pedras nos rins. Bastos (1995), em estudo semelhante realizado em restingas no Pará, apontou para a mesma espécie, lá conhecida como ajirú, o uso para dor de urina. Bastos aponta também o consumo e comércio dos frutos desta espécie.

As folhas da pitanga (Eugenia uniflora), são usadas para "abaixar a febre", para "curar gripe" e também é antidiarréica; a embaúba (Cecropia sp.), cujos "brotos" são utilizados em infusão para tratamento de coqueluche; a macela (Achyrocline satureoides), citada como calmante natural; a japecanga (Smilax rufescens), cujas raízes são colocadas em vinho ou cachaça por alguns dias e depois são consumidas como depurativa para o sangue, ("afinando o sangue") e também para tratamentos de anemia; a aroeira (Schinus terebinthifolius) é usada em tratamento de frieiras e para infecções da pele em geral, em banhos ou na forma de chás; o cardeiro-naná (Selenicereus setaceus), de "três quinas" é utilizado para problemas renais.

O diabetes, é uma das doenças mais difundidas entre os pescadores, assim como problemas associados à visão e à coluna. É interessante ressaltar que em todas as entrevistas os pescadores citaram estes três problemas de saúde. Muitos citaram também problemas respiratórios, como asma, bronquite e, no passado, tuberculose.

[...] tem um remédio bom pra diabete, o bajirú. Mas o pessoal daqui não valoriza, eu não sei porque [...] Valorizam aqui o saião, a erva-de-santa-maria, o cabelo-de-milho (Sr. Alex).

[...] eucalipto, que tem aqui na Álcalis. Umas folhas de eucalipto, daquele cheiroso. Porque tem duas marcas de eucalipto: tem um cheiroso e tem um outro que não é cheiroso. E bota debaixo da cama (Sr. Alex).

Outras plantas citadas com destaque para a cultura e tradição em Arraial do Cabo, foram o cipó-imbé (Philodendron corcovadense), vastamente utilizado na manufatura de cestarias em geral; folha-de-prata (Coccoloba alnifolia), cujo caule era utilizado na construção de casas de pau-a-pique; algumas Sapotaceae, cujo látex viscoso é usado na caça de pássaros e outros pequenos animais.

Muitas Bromeliaceae e Orchidaceae são citadas como sendo vistosas e interessantes na ornamentação dos quintais e casas. Entretanto, as Bromeliaceae, referidas como gravatás, têm outros usos, além do ornamental. Neoregelia cruenta, espécie bastante comum nas restingas, produz pequeno fruto comestível e muito apreciado. Sua bainha foliar é usada para confeccionar uma "bolsinha" para coletar frutos. Seu 
Tabela 3. Espécies cultivadas em vasos ou quintais das casas dos pescadores artesanais de Arraial do Cabo, RJ, em ordem alfabética do nome local.

\begin{tabular}{|c|c|c|}
\hline Família/Nome Científico & Nome Local & Usos e Partes utilizadas \\
\hline \multicolumn{3}{|l|}{ MALPIGHIACEAE } \\
\hline Malpighia glabra L. & acerola & Alimentar (fruto) \\
\hline \multicolumn{3}{|l|}{ APOCYNACEAE } \\
\hline $\begin{array}{l}\text { Allamanda cathartica } \mathrm{L} \text {. } \\
\text { LAMIACEAE }\end{array}$ & alamanda & Ornamental \\
\hline $\begin{array}{l}\text { Rosmarinus officinalis L. } \\
\text { LAMIACEAE }\end{array}$ & alecrim & Medicinal (folha); ritual (banho) \\
\hline Indet. & alfazema & Medicinal (folha; banhos) \\
\hline \multicolumn{3}{|l|}{ ARALIACEAE } \\
\hline Polyscias fruticosa (L.) Harms & alegria-da-casa; árvore-da-felicidade & Ritual ("traz felicidade e proteção à casa") \\
\hline \multicolumn{3}{|l|}{ PIPERACEAE } \\
\hline \multicolumn{3}{|l|}{ MYRTACEAE } \\
\hline Psidium cattleyanum Sabine & araçá * & Alimentar \\
\hline \multicolumn{3}{|l|}{ ASTERACEAE } \\
\hline Vernonia condensata Baker & assa-peixe & Medicinal (folha; para problemas digestivos) \\
\hline \multicolumn{3}{|l|}{ MYRTACEAE } \\
\hline Eugenia arenaria Cambess & cambuí * & Alimentar (fruto) \\
\hline \multicolumn{3}{|l|}{ COMMELINACEAE } \\
\hline $\begin{array}{l}\text { Dichorisandra thyrsiflora J.C. Mikan } \\
\text { POACEAE }\end{array}$ & \multicolumn{2}{|c|}{ POACEAE } \\
\hline Cymbopogon citratus (DC.) Stapf & capim-limão & $\begin{array}{l}\text { Medicinal (folha; febrífuga, anti-gripal, problemas } \\
\text { digestivos) }\end{array}$ \\
\hline \multicolumn{3}{|l|}{ ARACEAE } \\
\hline \multicolumn{3}{|l|}{ APOCYNACEAE } \\
\hline Thevetia peruviana (Pers.) K. Schum. & coração-de-cristo & Ritual \\
\hline LAMIACEAE & & \\
\hline \multicolumn{3}{|l|}{ VERBENACEAE } \\
\hline Lippia alba (Mill.) N.E. Br. & erva-cidreira & Medicinal (folha; contra resfriados, sedativa e cólicas) \\
\hline \multicolumn{3}{|l|}{ VERBENACEAE } \\
\hline $\begin{array}{l}\text { Vitex agnus-castus L. } \\
\text { LILIACEAE }\end{array}$ & erva-da-jurema & Medicinal (folha; “problemas femininos”) \\
\hline \multicolumn{3}{|l|}{ LILIACEAE } \\
\hline \multicolumn{3}{|l|}{ MYTACEAE } \\
\hline \multicolumn{3}{|l|}{ O. Berg } \\
\hline \multicolumn{3}{|l|}{ PHYTOLACCACEAE } \\
\hline $\begin{array}{l}\text { Petiveria alliacea } \mathrm{L} \text {. } \\
\text { RUTACEAE }\end{array}$ & guiné-piu-piu & Ritual \\
\hline Citrus sinensis (L.) Osbeck & laranja-da-terra & Medicinal (folha; febrífuga e antigripal) \\
\hline \multicolumn{3}{|l|}{ LAURACEAE } \\
\hline Laurus nobilis L. & louro & Medicinal (folha; contra problemas digestivos) \\
\hline \multicolumn{3}{|l|}{ LAMIACEAE } \\
\hline Ocimum basilicum $\mathrm{L}$. & manjericão & $\begin{array}{l}\text { Medicinal (folha; problemas digestivos); ritual } \\
\text { (banho) }\end{array}$ \\
\hline \multicolumn{3}{|l|}{ SOLANACEAE } \\
\hline Capsicum sp. & pimenta & Ritual (afasta "mau-olhado") \\
\hline \multicolumn{3}{|l|}{ EUPHORBIACEAE } \\
\hline $\begin{array}{l}\text { Jatropha gossypiifolia L. } \\
\text { LYRTA }\end{array}$ & pinhão-roxo & Medicinal (folha; banho) \\
\hline \multicolumn{3}{|l|}{ MYRTACEAE } \\
\hline Eugenia uniflora $\mathrm{L}$. & pitanga * & $\begin{array}{l}\text { Medicinal (folha; febrifuga e contra resfriados); al1- } \\
\text { mentar (frutos) }\end{array}$ \\
\hline CRASSULACEAE & & \\
\hline $\begin{array}{l}\text { Kalanchoe brasiliensis Cambess. } \\
\text { AMARANTHACEAE }\end{array}$ & saião & Medicinal (folha; cicatrizante) \\
\hline $\begin{array}{l}\text { AMARANTHACEAE } \\
\text { Alternanthera } \mathrm{sp} .\end{array}$ & & \\
\hline Alternanthera sp. & terramicina & Medicinal (folha; dores em geral) \\
\hline
\end{tabular}

* Espécies provenientes da restinga 


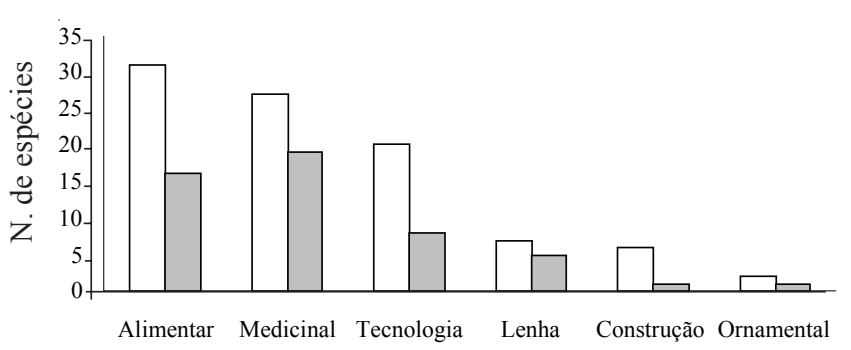

Categoria de uso

Figura 2. Número de espécies citadas por categorias de uso pelos pescadores artesanais da Praia Grande, Arraial do Cabo, RJ. $\square$ Espécies úteis por categoria de uso; Espécies exclusivas da categoria de uso.

valor reside ainda no fato de suas folhas em roseta constituir um reservatório de água doce onde podem ser encontrados pequenos animais usados como iscas na pesca.

Dentre as palmeiras, o guriri (Allagoptera arenaria) e o tucum (Bactris setosa) são aquelas que têm mais representação para os pescadores. Da bainha foliar do tucum, no passado, eram extraídas fibras para confeccionar linha de pesca e tarrafas para pescaria. Os pescadores afirmam que embora esta fosse técnica extremamente demorada, as redes produzidas com esta fibra eram mais resistentes e duráveis do que as atuais. uma rede de fibra de tucum durava quase 50 anos (Sr. Chonca). Para os pescadores, o guriri é o principal elemento indicador do ecossistema restinga; a sua freqüência e distribuição os auxilia na definição dos diferentes tipos de restingas.

Em geral os pescadores artesanais têm nos quintais de suas casas um pequeno espaço reservado ao cultivo de espécies para diferentes fins, principalmente medicinais e condimentares, e também de usos religiosos e alimentares (Tab. 3). Têm maior interesse em cultivar espécies comestíveis e medicinais, sendo a maioria exótica. Apenas $22,2 \%$ das espécies cultivadas são nativas da restinga, indicando a influência de diferentes culturas na formação do conhecimento das plantas na região. Dentre as espécies nativas da restinga, sobressaem as que produzem os frutos mais apreciados por eles, provavelmente, por chegarem das suas pescas e caminhadas pela restinga e jogarem as sementes no quintal.

Quando se compara os resultados obtidos nesta pesquisa etnobotânica com outros estudos realizados em trechos do litoral brasileiro, verifica-se que há muitas espécies e usos comuns, apesar da extensão da costa brasileira. Esses elementos, em grande parte, são de influências semelhantes na sedimentação das bases sócio-culturais dos habitantes do litoral (Adams 2000). Os valores obtidos para o índice de diversidade, possibilitam comparações dos dados obtidos (Tab. 4).

No município de Marapim, Pará, Bastos (1995) encontrou 28 espécies da restinga utilizadas como medicinais pelos pescadores, entre as quais três são comuns ao presente estudo: Chrysobalanus icaco chamado pelos pescadores de ajiru ou ajurú, cuja raiz é empregada, em forma de chá, para dor de urina, afirmando também que os frutos são comestíveis e comercializados; Anacardium occidentale, o caju, com fruto empregado para diversos fins e cuja casca é empregada em banho de asseio em pós-parto como cicatrizante; Tapirira guianensis, tapiririca, de cuja casca se faz xarope expectorante. Os usos das espécies e seus nomes comuns pouco diferem, embora seja grande a distância entre as duas áreas.

$\mathrm{Na}$ Área de Proteção Ambiental de Guaraqueçaba, no Paraná, Lima et al. (2000), realizando 75 entrevistas em 10 comunidades, obtiveram a citação de 445 espécies botânicas, dentre as quais $323(72,6 \%)$ citadas como de uso medicinal, sendo esta a categoria de maior uso. Outras categorias em destaque foram alimentação, desdobro da madeira e artefatos de pesca. Estas mesmas categorias também foram aquelas de maior destaque em Arraial do Cabo. Das espécies citadas por Lima et al. (2000), 19 são comuns ao presente estudo. Estes autores assinalaram que a maior concentração de conhecimento etnobiológico está nos habitantes na faixa de 51 a 80 anos de idade; nas faixas mais novas estes conhecimentos estão diluídos.

Em Ponta do Almada e Camburiú, São Paulo, Hanazaki et al. (2000) realizaram 102 entrevistas, obtendo informações sobre 227 etnoespécies nas categorias de uso alimentar, medicinal e artesanal.

Rossato et al. (1999) apresentaram dados sobre o uso de plantas em cinco comunidades caiçaras no litoral norte de São Paulo. Pesquisando sobre quatro categorias de uso, encontraram 276 plantas, 88 das quais como medicinais e 77 para construção e trabalhos manuais.

Na Ilha de Búzios, São Paulo, Begossi et al. (1993) trabalharam com quatro categorias de uso e 56 informantes da comunidade pesqueira, encontrando 128 espécies utilizadas, 18 das quais comuns ao presente estudo.

Em Gamboa, Ilha de Itacuruçá, Rio de Janeiro, Figueiredo et al. (1993), contando com 58 informantes, citaram 90 espécies das quais 18 são comuns ao presente estudo. A categoria medicinal foi a mais citada e considerada de muita importância pela comunidade. 
Lima et al. (2000), Hanazaki et al. (2000), Rossato et al. (1999), Begossi (1996), Begossi et al. (1993) e Figueiredo et al. (1993) utilizaram o índice de diversidade de Shannon $\left(H^{\prime}\right)$ para estabelecer comparações entre os resultados obtidos em seus estudos com outros trabalhos etnobotânicos (Tab. 4).

$\mathrm{O}$ índice de diversidade, amplamente empregado em ecologia, vem sendo utilizado mais recentemente em trabalhos etnobotânicos com a finalidade de avaliar a diversidade do conhecimento etnobotânico. Lima et al. (2000) afirmaram que índices elevados em geral relacionam áreas relativamente bem conservadas associadas à populações com significativo conhecimento etnobotânico.

O índice de Shannon $\left(\mathrm{H}^{\prime}\right)$ obtido a partir das entrevistas em Arraial do Cabo foi de 1,78 (base 10) e 4,10 (base e), denotando que os pescadores possuem ainda bom conhecimento dos recursos da biodiversidade. Comparações realizadas com os seis trabalhos acima citados mostraram que a comunidade de pescadores de Arraial do Cabo situa-se em quarto lugar segundo este parâmetro (Tab. 4). Os valores obtidos para o presente estudo estão próximos àqueles encontrados em estudos realizados no litoral de São Paulo, embora estes sejam realizados em área de mata atlântica que, de modo geral, apresenta maior diversidade biológica que a restinga.

Como conclusões, pode-se destacar que a atividade pesqueira no município de Arraial do Cabo, que tem uma das mais antigas e tradicionais colonias de pescadores do Estado do Rio de Janeiro, ainda é grande. São praticadas diversas modalidades de pesca, tanto as tradicionais como as mais modernas. A criação da RESEX reforçou a atividade de pesca, ao mesmo tempo em que trouxe maior controle da exploração sustentável dos recursos naturais renováveis.

A pesca artesanal, aliada a outras questões sociais, é responsável pela identidade de pescador cabista que sempre apresentou forte ligação com o meio ambiente e seus recursos. Os pescadores artesanais, cabistas, mantêm um saber amplo sobre a natureza (localização geográfica, tipos de vegetação, uso de espécies, épocas de floração, entre outros) e o saber é vivenciado na família e na comunidade. O saber tradicional encontrase mantido especialmente entre os pescadores mais idosos. Os jovens de Arraial do Cabo não tem sido atraídos para as atividades de pesca. Os mais idosos alegam que eles também não têm interesse no conhecimento tradicional, embora a metodologia empregada não tenha permitido constatar esta alegação.

Os pescadores reconhecem e definem a restinga e suas diferentes formações. Reconhecem as alterações ocorridas no ambiente ao longo de seu tempo de vida, a chegada de plantas que com o tempo se tornaram "pragas", como as casuarinas, por exemplo.

Das 36 etnoespécies encontradas nas restingas, a categoria que mais agrega espécies é a de uso medicinal, seguido de alimentares. Embora não se possa afirmar que a comunidade dependa, para a cura de suas doenças, de plantas medicinais coletadas na restinga ou cultivadas em quintais, as plantas são muito importantes no seu dia-a-dia. Em relação às plantas comestíveis, reconhecem e citam, repetidas vezes, que a restinga é rica em saborosos e nutritivos frutos, ressaltando, especialmente as virtudes dos frutos de espécies de Myrtaceae.

Empregam espécies na construção ou conserto de barcos, casas e outras tecnologias e também em

Tabela 4. Comparação das informações etnobotânicas compiladas de estudos realizados em ecossistemas costeiros brasileiros. Veg- tipo de vegetação; Abr.- abrangência do estudo (número de categorias de uso); N. Inf.-número de informantes; N. Esp.-número de espécies citadas; N. cit.-número de citações; N. esp. comuns - número de espécies comums com o presente estudo; $H^{\prime}$ - Índice de Shannon (B.10 - base, B.e-base e); R- restinga; Ma- mata atlântica; Mg- manguezal; C- áreas cultivadas ou roças; (-) indica ausência de informação.

\begin{tabular}{|c|c|c|c|c|c|c|c|c|c|}
\hline Fonte & Local & Veg. & Abr. & N. inf. & N. esp. & N. cit. & $\begin{array}{l}\text { N. esp. } \\
\text { comuns }\end{array}$ & $H^{\prime}$ B. 10 & B.e \\
\hline Figueiredo et al. 1993 & Gamboa (Ilha de Itacuruça), RJ & $\mathrm{Ma}$ & 3 & 58 & 90 & 558 & 12 & 1,65 & - \\
\hline Begossi et al. 1993 & Ilha de Búzios, SP & $\mathrm{Ma}, \mathrm{C}$ & 4 & 56 & 128 & - & 18 & 1,57 & - \\
\hline Bastos 1995 & Marapanim, PA & $\mathrm{R}, \mathrm{Mg}$ & 4 & - & - & 27 & 1 & - & - \\
\hline Rossato et al. 1999 & SP & $\mathrm{Ma}$ & - & 162 & 277 & 3.109 & 7 & 2,06 & - \\
\hline Lima et al. 2000 & Guaraqueçaba, PR & $\mathrm{Ma}$ & 14 & 90 & 445 & 3.400 & 19 & 2,38 & 5,48 \\
\hline \multirow{2}{*}{ Hanazaki et al. 2000} & Ponta do Almada, SP & $\mathrm{Ma}$ & 3 & - & 152 & - & 22 & 1,99 & 4,59 \\
\hline & Praia de Camburiú, SP & $\mathrm{Ma}$ & 3 & - & 162 & - & 22 & 1,98 & 4,57 \\
\hline Este trabalho & Arraial do Cabo, RJ & $\mathrm{R}$ & 6 & 15 & 68 & 444 & - & 1,78 & 4,10 \\
\hline
\end{tabular}


artesanato, afirmando que é necessário o conhecimento sobre o modo e a época de proceder à coleta do vegetais ou de suas partes para que se obtenha sucesso no emprego dos mesmas. Além do tamanho e do porte adequados, as fases da lua regulam a coleta. Entretanto, embora reconheçam que alguns artefatos produzidos a partir de técnicas tradicionais e da utilização de produtos naturais, são mais eficientes do que alguns artefatos oferecidos no comércio, não se utilizam mais da tecnologia aprendida ao longo da vida para fabricá-los. A rede e a linha de pesca utilizada hoje, sempre de nailon, ilustram esta opção.

Parece estratégico que, para a conservação do conhecimento tradicional e do meio ambiente, deve-se estimular a criação de espaços que possibilitem o compartilhamento do saber entre os jovens e o seguimento de mais idade da comunidade, bem como o estabelecimento de hortos para contribuir com a manutenção e a valorização das tradições sobre os usos de plantas.

\section{Agradecimentos}

Aos pescadores artesanais de Arraial do Cabo, pelos ensinamentos e hospitalidade nos trabalhos de campo; à Associação de Pescadores de Arraial do Cabo (AREMAC), à sede do IBAMA em Arraial do Cabo e ao IEAPM (Instituto de Estudos do Mar "Almirante Paulo Moreira"), pelo apoio no período dos trabalhos de campo; à CAPES (Coordenação de Aperfeiçoamento de Pessoal de Nível Superior) e à coordenação da Pós Graduação em Ciências Ambientais da Universidade Federal Rural do Rio de Janeiro, pelo apoio e bolsa de estudos concedida à primeira Autora; aos botânicos Graziela M. Barroso, Cyl Farney C. de Sá, Dorothy S. D. de Araújo, Haroldo C. de Lima, Elsie F. Guimarães, Carine G. Pinto, Genise V. Freire, Solange Pessoa, Marcus Nadriz, Lucia Freire de Carvalho, Bruno Kurtz, Alexandre Quinet, Regina P. Andreata, Massimo Bovini, Ronaldo Marguete, pela identificação do material botânico; Alexandre G. Christo, pelo auxílio na confecção da Figura 1.

\section{Referências bibliográficas}

Adams, C. 2000. As populações caiçaras e o mito do bom selvagem: a necessidade de uma nova abordagem interdisciplinar. Revista de Antropologia 43(1): 145-181.

Álcalis - Companhia Nacional de Álcalis. 2001 Disponível em: <http://www.alcalis.com.br/oquee/index.htm>. Acesso em 6/dezembro/2001.
Alexiades, M. N. 1996. Selected guidelines for ethnobotanical research: a field manual. The New York Botanical Garden, Bronx.

Araujo, D. S. D. 1997. Cabo Frio Region-South-eastern Brazil. Pp. 373-375. In: WWF \& IUCN (Eds.) Centres of plants diversity: a guide and strategy for their conservation. The Americas. Cambridge, IUCN Publications Unit., v. 3.

Araujo, D. S. D. 2000. Análise florística e fitogeográfica das restingas do Estado do Rio de Janeiro. Tese de Doutorado. Universidade Federal do Rio de Janeiro, Rio de Janeiro.

Araujo, D. M. 1965. Última estrada em Arraial do Cabo - 5 a 20 de janeiro de 1964. Rio de Janeiro, Revista do Instituto de Ciências Sociais 2(1): 211-214.

Barbiere, E.B. 1984. Cabo Frio e Iguaba Grande, dois microclimas distintos a um curto intervalo espacial. Pp. 3-13. In: L. D. Lacerda; D. D. D. Araújo; R. Cerqueira \& B. Turcq (eds.). Restingas: Origem, Estrutura, Processos. CEUFF, Niterói.

Bastos, M. N. C. 1995. A importância das formações vegetais da restinga e do manguezal para as comunidades pesqueiras. Boletim do Museu Paraense Emílio Goeldi, ser. Antropologia 11(1): 41-56.

Beck, H. T. \& Ortiz A. 1997. Proyecto etnobotánico de la comunidad Awá en el Ecuador. Pp. 159-176. In: M. Rios \& H.B. Pedersen (eds.). Uso y Manejo de Recursos Vegetales. Memorias del II Simposio Ecuatoriano de Etnobotánica y Botánica Economica, Quito.

Begossi, A.; Leitão-Filho, H. F. \& Richerson, R. J. 1993. Plant uses in a Brazilian coastal fishing community (Buzios Island). Journal of Ethnobiology 13(2): 233-256.

Begossi, A. 1996. Use of ecological methods in Ethnobotany: Diversity indices. Economic Botany 50(3): 280-289.

Bernard, R. H. 1989. Research methods in cultural anthropology. SAGE Publications, Inc., Londres.

Brasil. 1998. Ministério do Meio Ambiente, dos Recursos Hídricos e da Amazônia Legal. Primeiro Relatório Nacional para a Conservação sobre Diversidade Biológica: Brasil, Brasília.

Britto, R. C. de C. 1999. Modernidade e tradição - construção da identidade social dos pescadores de Arraial do Cabo. Eduff, Niterói.

Diegues, A. C. 1988. A pesca artesanal no litoral brasileiro: cenários e estratégias para sua sobrevivência. Rio de Janeiro, Proposta - Experiências em Educação Popular (publicações avulsas). FASE (38): 4-7.

Diegues, A. C. 2000. Etnoconservação da Natureza: Enfoques Alternativos. Pp. 1-46. In: Diegues, A.C. (org.). Etnoconservação: novos rumos para a proteção da natureza nos trópicos. NAPAUB, São Paulo.

Figueiredo, G. M.; Leitão-Filho, H. \& Begossi, A. 1993. Ethnobotany of Atlantic Forest Coastal Communities: diversity of plant uses in Gamboa (Itacuruça Island, Brazil). Human Ecology 2(4): 419-430. 
Fonseca, V. S. \& Sá, C. F. C. 1997. Situación de los estudios etnobotánicos en ecosistemas costeros de Brasil. Pp. 5781. In: M. Rios \& H.B. Pedersen (eds.). Uso y Manejo de Recursos Vegetales. Memorias del II Simposio Ecuatoriano de Etnobotánica y Botánica Economica, Quito.

Fontenelle, L. F. 1960. A dinâmica dos grupos domésticos no Arraial do Cabo. Serviço Social Rural (Edições SSR) Estudos, Rio de Janeiro.

Gottlieb, O. R.; Kaplan, M. A. C. \& Borin, M. R. M. B. 1996. Biodiversidade. Um enfoque químico-biológico. Editora UFRJ, Rio de Janeiro.

Hanasaki, N.; Tamashiro, J. Y; Leitão-Filho, H. \& Begossi, A. 2000. Diversity of plant uses in two caiçara communities from the Atlantic Forest coast, Brazil. Biodiversity and Conservation 9: 597-615.

IBGE - Instituto Brasileiro de Geografia e Estatística. Resultados do Universo do Censo 2000. Disponível em: $<$ http://www.ibge.gov.br/cidadesat/default.php $>$. Acesso em: 7/dezembro/2001.

Kneip, L. M. \& Pallestrini, L. 1984. Restingas do Estado do Rio de Janeiro (Niterói a Cabo Frio): 8 mil anos de ocupação humana. Pp. 139-146. In: L. D. Lacerda; D. D. D. Araújo; R. Cerqueira \& B. Turcq (eds.). Restingas: origem, estrutura, processos. CEUFF, Niterói.
Lima, R. X.; Silva, S. M.; Kuniyoshi, Y. S. \& Silva, L. B. 2000. Etnobiologia de comunidades continentais da Área de Proteção Ambiental de Guaraqueçaba, Paraná, Brasil. Etnoecológica 4(6): 33-55.

Magurran, A. E. 1988. Ecological diversity and its measurement. Princeton University Press, New Jersey.

Martin, G. J. 2000. Etnobotánica - Manual de métodos: manuales de conservación, Série Pueblos y Plantas 1,WWF. Ed. Nordan-Comunidad, Uruguay.

Phillips, O. \& Gentry, A. H. 1993. The useful plants of Tambopata, Peru. I: Statistical hypotheses tests with a new quantitative technique. Economic Botany 47: 33-43.

Prado, S. M. 2002. Da anchova ao salário mínimo: uma etnografia sobre injunções de mudança social em Arraial do Cabo, RJ. Eduff, Niterói.

Rossato, S. C.; Leitão-Filho, H. F. \& Begossi, A. 1999. Ethnobotany of caiçaras of the Atlantic Forest Coast (Brazil). Economic Botany 53(4): 387-395.

Sampaio, T. 1987. O tupi na geografia nacional. Brasiliana, Rio de Janeiro. 